\title{
Evaluation of the Effect of Glass Granule Size on Water Damage Performance of Asphalt Mixtures
}

\author{
Erol İSKENDER ${ }^{1}$ \\ Aytuna SAYIN ${ }^{2}$ \\ Atakan AKSOY ${ }^{3}$ \\ Cansu ISKENDER ${ }^{4}$
}

\begin{abstract}
Economic growth and the increase in the population trigger consumption and increase the amount of waste produced. One of the resulting wastes is glass and using of these large amount of glass waste materials by environmental methods is seen as an important issue. On the other hand, there are difficulties due to the decrease of natural resources in the supply of aggregates used in asphalt pavements. In this study, the use of waste glass instead of natural aggregates in asphalt pavements was investigated in terms of water damage. In addition to base bitumen, hydrated lime modified and SBS modified bitumen were used in experimental studies. The waste glass was added in two different sizes (as filler materials and $2 \mathrm{~mm}$ sized fine aggregate) and three addition ratios $(20 \%, 30 \%$ and $40 \%)$ instead of basalt aggregates. The asphalt mix samples produced in optimum bitumen contents were evaluated for water damage by AASHTO T 283 method. Asphalt mixture with $20 \%$ glass filler showed the highest water damage resistance. Among the options where the glass aggregate size was chosen as $2 \mathrm{~mm}$, the highest water damage resistance was realized at addition rate of $30 \%$. Both hydrated lime and SBS polymer were effective in improving water damage resistance. However, the highest tensile strength ratio was obtained with hydrated lime. The optimum bitumen contents of the mixtures with glass aggregates produced with both base and modified bitumen were decreased compared to that produced entirely with basalt aggregate. According to the test results, it is understood that the filler materials produced from waste glasses can be used instead of natural aggregate filler.
\end{abstract}

Keywords: Waste glass, glass granule asphalt pavements, water damage, indirect tensile strength ratios, SBS polymer, hydrated lime.

Note:

- This paper has been received on January 2, 2019 and accepted for publication by the Editorial Board on May 30, 2019.

- Discussions on this paper will be accepted by January 31, 2021.

- https://dx.doi.org/10.18400/tekderg.504698

1 Karadeniz Technical University, Civil Engineering Department, Trabzon, Turkey - eiskender@ktu.edu.tr https://orcid.org/0000-0001-7934-839X

2 General Directorate of Highways, Tenth Regional Directorate, Trabzon, Turkey - asayin22@hotmail.com https://orcid.org/0000-0002-2442-5324

3 Karadeniz Technical University, Civil Engineering Department, Trabzon, Turkey - aaksoy@ktu.edu.tr https://orcid.org/0000-0001-5232-6465

4 Karadeniz Technical University, Civil Engineering Dep., Trabzon, Turkey - cansuiskender3@gmail.com https://orcid.org/0000-0003-2856-4409 


\section{INTRODUCTION}

Since aggregate constitutes a large portion of the asphalt mix, comprehensive understanding of the engineering properties of recycled aggregate can provide tremendous benefits in terms of environmental protection and efficient use of resources. Recognizing this fact, considering the recovered aggregate or mixture, such as reclaimed asphalt pavement (RAP), recycled construction aggregate (RCA), recycled glass, etc., the reported work and research on their use have increased throughout the world in the last two decades [1].

Large quantities of waste are produced with rapid economic growth and ever-increasing consumption. Among these is the waste glass material being an important part. The glass material is non-metallic and inorganic, neither burnable nor decomposable, which can be difficult to recover. The performance of the asphalt concrete in which a part of the crushed fine aggregate is replaced by the crushed glass material has been examined. Glass materials are fragile and silicon rich, therefore the basic technical indices of glass-asphalt concrete are the resistance to water and strength [2].

Glassphalt is basically the same as conventional hot mix asphalt but it contains grounded crushed glass instead of stone aggregate (basalt, limestone, etc.). Glass aggregate of 3/8-inch and finer grade is recommended for the surface layer [3].

The amount and size of the added glass cullet in the aggregate mixture affects the mechanical properties of the asphalt mixture. Increasing the amount of glass cullet reduces permanent deformation of asphalt samples. For upper layer, behavior of glassphalt may be satisfactory for quantity of glass up to $15 \%$ [2]. Adding broken glass particles up to $15 \%$ to the aggregate mixture improves the fatigue behavior of the asphalt mixture and increases the stiffness modulus. But when the glass aggregate ratio exceeds $15 \%$, reduction occurs $[4,5]$. Skid resistance, resilient modulus and moisture sensitivity of asphalt mixture containing crushed glass aggregate were evaluated. The fine aggregates, up to $15 \%$ of the total aggregate content, were replaced with glass particles in three different gradations. It was found that the crushed glass particles improved skid resistance by up to $20 \%$ [6].

The size of the glass aggregate also affects the performance of the asphalt mixture. The maximum size of the glass aggregate is generally recommended as $4.75 \mathrm{~mm}$ [4, 5, 7-10]. Some researchers suggest that $2.36 \mathrm{~mm}$ maximum glass aggregate size and $10 \%$ utilization rate are more appropriate [11].

In a study on the dynamic characteristics of glassphalts, four percent of hydrated lime was used as antistripping agent. Stiffness modulus of glassphalt mixtures increased with respect to conventional asphalt-mix. In addition, 3-5\% hydrated lime was used as an anti-stripping agent and it was found that a glassphalt mixture containing hydrated lime has a greater stiffness modulus than normal specimens [12]. In another study, the effect of hydrated lime on the rutting, water damage and stability properties of the glassphalt mixtures was investigated. Hydrated lime was added to both bitumen and aggregate mixture. Glassphalt mixture with hydrated lime showed higher water damage and rutting resistance. Moreover, the stability values of the samples increased [13].

In a study in the literature, among the materials used in the tests, heavy duty bitumen (AH70) and SBS modified asphalt, limestone aggregate and crushed recycled glasses were used. The Marshall test was used to investigate the effect of the optimum asphalt content, volume 
properties and asphalt concrete strength when several different types of crushed glass were added. The test data obtained from the Modified Lottman test, the freeze-thawing test and the submerged wheel tracking test show that glass-asphalt concrete is more resistant to water damage than normal asphalt concrete. Properties can be improved by using liquid antistripping agents or hydrated lime additive. The high temperature stability and fatigue performance of the glass-asphalt concrete were also tested and the results were satisfactory. The research has shown that it is possible to recycle and use waste glass in asphalt concrete. The satisfactory performance of the upper asphalt coating layers can be achieved with a dosage of $10-15 \%$ by weight. Larger quantities can induce stripping problems and make the upholstery susceptible to water damage. $25 \%$ or more of the glass contribution can only be applied to the middle or lower layer [2].

In the literature, it is recommended that the maximum glass aggregate size should be chosen as $4.75 \mathrm{~mm}$ and the use of larger glass particle sizes should be avoided. The results of water immersed rutting tests show that the dynamic stability of samples with a maximum glass particle size of $9.5 \mathrm{~mm}$ is lower than that of samples with a maximum size of $4.75 \mathrm{~mm}$. Also, there is not much more surface area in the $9.5 \mathrm{~mm}$ blend. For this reason, the maximum size of $9.5 \mathrm{~mm}$ is not suitable for use in asphalt mixtures and the work adopts a maximum size of $4.75 \mathrm{~mm}[14]$.

The use of primary aggregate in a road asphalt mixture layer or aggregate asphalt mixture is seen as a waste of a limited natural resource. Recycled glass can be considered as valuable alternative aggregate resources for asphalt mixture production. The purpose of this work is to evaluate the use of waste glass in asphalt mixtures as secondary aggregates according to Marshall Specifications. The study is based on the combination of glass with six dimensions $(1 / 2,3 / 8$, No. 4 , No. 8 , No. 50 and No. 200$)$ and two contents (50\% and $100 \%)$ according to the weight of each piece. Secondly, it is used as additive materials containing three times (1, 2 and 4\%) total mixture weight of glass and two dimensions of glass (No. 50 and No. 200). The engineering properties of the control and glass mixtures (stability, flow, volume density and percentage of voids in the total mixture) were evaluated by the Marshall Test. The study results show that Marshall Stability for glass fiber is higher than the control mixture when glass gradation (No. 8 and No. 200) are used as secondary aggregates in the asphalt mix, respectively [15].

Through effective marketing trials, the material is generally sold between U.S. $\$ 1.00$ to $\$ 2.00$ per ton for glass waste versus $\$ 5.00$ to $\$ 7.00$ per ton for conventional control aggregate. The most successful and predominant use is in the manufacture of asphalt, commonly referred to as "glassphalt". Based on the customer, asphalt plants throughout the Northeast and other areas of the USA routinely blend the natural aggregate with up to $10 \%$ processed glass for making asphalt mixtures. The amount of glass is limited to $10 \%$ in order to avoid water damage (i.e. the separation of the glass component from the binders). This application also requires the proper sizing of the glass aggregate, but most importantly, the quantities of glass aggregate required for asphalt producers to continually incorporate the material into their product are often prohibitive [16].

Glass recycling rate in Turkey compared with Western European countries is still quite low. Glass unlike all other materials can be converted endlessly and does not affect the recycling process. The quality of the final product is not affected in a negative way. Glass waste, especially glass packaging, is recycled and recycled into glass as raw material, contributing 
not only to the economy but also to the environment as it reduces energy use and greenhouse gas emissions significantly. The volume of recycled glass reached 141 thousand tons in 2015 from 67 thousand tons per annum [17]. Glass packaging recycling rates of European countries are quite high. 94.18\% in Switzerland, 93.76\% in Luxemburg, and 92.94\% in Sweden, giving the highest return-on-rates. The average of EU-27 countries reaches to $70.28 \%$ value and unfortunately Turkey is one of the countries located at the bottom of the list with $25.81 \%$ with low performance [18].

The aim of this research is to investigate the performance of glass admixtures of different sizes in asphalt mixtures using basalt aggregates. Glass was used at different additive ratios. The glass admixture in different proportions was used with different sizes, hydrated lime and SBS polymer options. For selected multi-additive alternatives, the possibility of using recycled glass as aggregate is examined. Combined performances were questioned, especially in terms of water damage, under specified parameters.

\section{MATERIALS AND METHOD}

\subsection{Materials}

Aggregates were obtained by crushing rocks supplied from the basalt quarry in Trabzon (in Turkey). The general physical properties of basalt aggregates were presented in Table 1.

Table 1 - Engineering properties of basalt aggregates

\begin{tabular}{lll}
\hline Properties & Test Method & Value \\
\hline Specific gravity (coarse agg.) & ASTM C 127 & \\
Bulk & & 2.684 \\
Apparent & & 2.744 \\
Specific gravity (fine agg.) & ASTM C 128 & \\
Bulk & & 2.656 \\
Apparent & & 2.754 \\
Specific gravity (filler) & & 2.821 \\
Los Angeles abrasion (\%) & ASTM C-131 & 12 \\
Flakiness (\%) & BS 812 (Part 105) & 14 \\
Stripping resistance (no additive) (\%) & ASTM D-1664 & $35-40$ \\
Water absorption (\%) & ASTM C-127 & 0.81 \\
Soundness in NaSO $(\%)$ & ASTM C-88 & 0.92 \\
Plasticity index for sandy aggregate & TS 1900 & non- plastic \\
\hline
\end{tabular}

In the study, 50/70 penetration grade bitumen obtained from Tüpraş Kırıkkale refinery was used. Some properties of used bitumen were given in Table 2. 
Table 2 - Properties of used base bitumen

\begin{tabular}{lll}
\hline Test & Test Method & Value \\
\hline Specific gravity $\left(25^{\circ} \mathrm{C}\right)$ & ASTM D-70 & 1.025 \\
Softening point $\left({ }^{\circ} \mathrm{C}\right)$ & TS EN 1427 & 50 \\
Flash point $($ Cleveland $)$ & TS EN ISO 2592 & 240 \\
Penetration $\left(25^{\circ} \mathrm{C}\right)$ & TS EN 1426 & 63 \\
Ductility $\left(25^{\circ} \mathrm{C}\right)$ & ASTM D-113 & $100+$ \\
\hline
\end{tabular}

Dense graded aggregate combination (Type-1) was used in accordance with the Turkish Highways Technical Specification [19]. The maximum aggregate size was selected as 19 mm. Aggregate gradation was given in Figure 1.

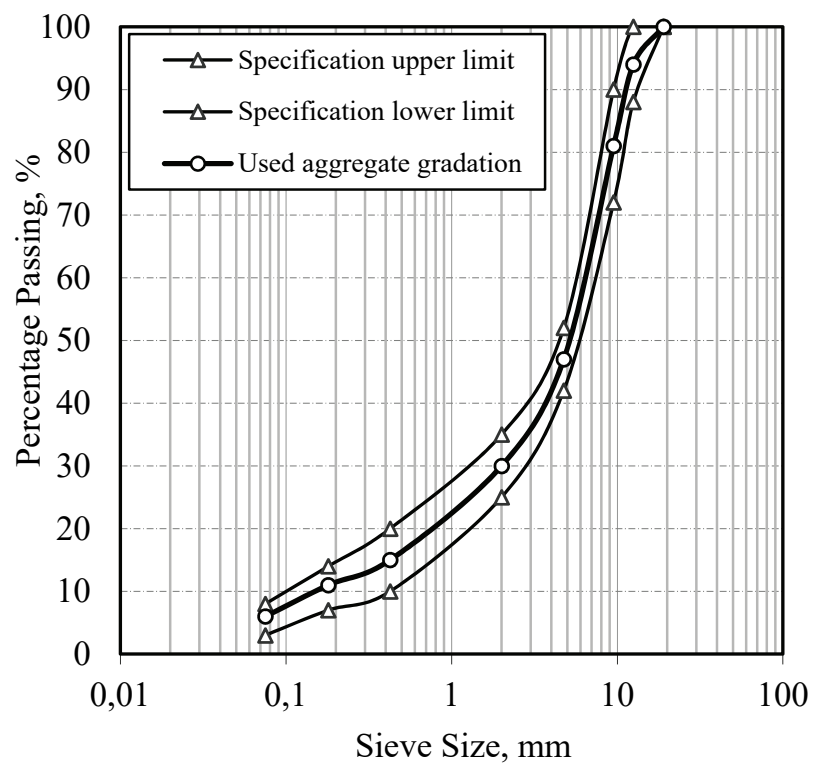

Figure 1 - Selected dense aggregate gradation chart

In the work, waste glass, which is the production residue of glass processing factories, is used as aggregate substituted for basalt aggregates. The waste glasses are in colorless form and consists of a mixture of tempered and construction glasses. The glasses were sieved from standard ASTM sieves after crushed in a mini crusher in the laboratory. Two different sized glass aggregate were used substituted for basalt aggregate. Glass aggregates, at sizes less than $0.075 \mathrm{~mm}$ (filler size) and between $2 \mathrm{~mm}$ and $0.425 \mathrm{~mm}$, were used at $20 \%, 30 \%$ and $40 \%$ instead of basalt aggregate. Main oxide analysis of glass aggregates was done and results are shown in Table 3. 
Evaluation of the Effect of Glass Granule Size on Water Damage Performance of ...

Table 3 - Chemical analysis test results of waste glasses particles [20]

\begin{tabular}{lll}
\hline Components & Formula & Value (\%) \\
\hline Silicium dioxide & $\mathrm{SiO}_{2}$ & 70.4 \\
Aluminum oxide & $\mathrm{Al}_{2} \mathrm{O}_{3}$ & 0.11 \\
Titanium dioxide & $\mathrm{TiO}_{2}$ & 0.086 \\
Ferrous oxide & $\mathrm{Fe}_{2} \mathrm{O}_{3}$ & 0.205 \\
Magnesium oxide & $\mathrm{MgO}$ & 5.03 \\
Calcium oxide & $\mathrm{CaO}$ & 7.01 \\
Sodium oxide & $\mathrm{Na}_{2} \mathrm{O}$ & 12.95 \\
Potassium oxide & $\mathrm{K}_{2} \mathrm{O}$ & 0.51 \\
Sulfur trioxide & $\mathrm{SO}_{3}$ & 0.23 \\
\hline
\end{tabular}

In addition to base bitumen, SBS (Kraton D1101) and hydrated lime (SKK 80-T) modified bitumen were also used. Chemical properties of hydrated lime illustrated in Table 4. Hydrated lime (HL) and SBS addition ratios in bitumen were selected as $2 \%$ and $5 \%$, respectively. Modified bitumen were prepared with high shear mixer. The modification was carried out at a temperature of $160^{\circ} \mathrm{C}$ for 30 minutes at a stirring speed of $4500 \mathrm{rpm}$.

Table 4 - Chemical properties of used hydrated lime [20].

\begin{tabular}{lll}
\hline Chemical properties & Test standard & Value \\
\hline Total $\mathrm{CaO}(\%)$ & EN 459-2 & 84.66 \\
Active $\mathrm{Ca}(\mathrm{OH})_{2}(\%)$ & TS 32 & 82.23 \\
$\mathrm{MgO}(\%)$ & EN 459-2 & 4.05 \\
Total CaO+MgO (\%) & TS & 89.17 \\
Ignition loss (\%) & EN 459 & 23.17 \\
Acid-insoluble (\%) & TS 32 & 1.39 \\
$\mathrm{R}_{2} \mathrm{O}_{3}(\%)$ & TS 32 & 0.44 \\
$\mathrm{SO}_{3}(\%)$ & EN 459 & 1.51 \\
$\mathrm{CO}_{2}(\%)$ & EN 459 & 3.77 \\
${\mathrm{Density}\left(\mathrm{kg} / \mathrm{m}^{3}\right)}$ & EN 459 & 473 \\
\hline
\end{tabular}

\subsection{Mixture Design and Sample Production}

Dense graded asphalt concrete design was done with the Marshall Design method (ASTM D 1559). Optimum bitumen contents for conventional and modified bitumen were determined separately. The optimum bitumen content was taken as the percentage of bitumen corresponding to $4 \%$ air voids and designated as $5.30 \%, 5.63 \%$ and $5.42 \%$ for base bitumen, 
hydrate lime modified bitumen and SBS modified bitumen, respectively. According to bitumen - glass aggregate ratio combinations optimum bitumen ratios were determined and illustrated in Table 5.

Table 5 - Optimum bitumen contents of asphalt mixtures with glass aggregates

\begin{tabular}{lllllllc}
\hline & $\begin{array}{l}\text { Basalt } \\
\text { aggregate }\end{array}$ & \multicolumn{3}{l}{$\begin{array}{l}\text { Glass filler substituted } \\
\text { for basalt filler }\end{array}$} & \multicolumn{2}{l}{$\begin{array}{l}\text { Glass aggregate }(0.475-2.0 \\
\mathrm{mm})\end{array}$} \\
\cline { 2 - 8 } substitute for basalt
\end{tabular}

\subsection{Method}

The glass admixtures were added to the aggregate mix substituted for the basalt aggregate of its size. Glass wastes were broken and used in place of fillers and basalt aggregates in the range of $0.425-2.0 \mathrm{~mm}$. Dense graded asphalt concrete mixtures with base bitumen, hydrated lime modified bitumen and SBS modified bitumen were produced and the resistance to water damage was evaluated by AASHTO T283 method.

Samples used for the AASHTO T283 method are divided into two groups, unconditioned and conditioned. The samples in conditioned group are saturated with water between $70 \%$ and $80 \%$ with a vacuum pycnometer. Samples that reach more saturation are deemed deformed and are not used in subsequent tests. The samples are then tightly covered with a plastic film and placed in a plastic bag containing $10 \pm 5 \mathrm{ml}$ of water. Saturated samples are kept frozen at $-18 \pm 3^{\circ} \mathrm{C}$ for minimum 16 hours. The samples, which have completed the freezing process, are placed in a water bath at $60 \pm 1^{\circ} \mathrm{C}$ for $24 \pm$ ? hours without waiting. After water bath, plastic bag and film are removed. Conditioned samples are placed in a water bath at $25 \pm 0.5^{\circ} \mathrm{C}$ for $2 \mathrm{~h} \pm 10 \mathrm{~min}$. Samples removed from the water bath are tested by indirect tensile strength method. Samples in unconditioned group are tested after the water bath at $25 \pm 0.5^{\circ} \mathrm{C}$ for $2 \mathrm{~h} \pm 10 \mathrm{~min}$ directly. During the test, the maximum compressive strength is recorded in the test device. Using the recorded values and sample sizes, the tensile strengths are calculated by Equation 1 [21].

$\mathrm{S}_{t}=(2000 \cdot \mathrm{P}) /(\pi \cdot \mathrm{t} \cdot \mathrm{D})$

Where:

$\mathrm{S}_{\mathrm{t}}$ : tensile strength, $\mathrm{kPa}$

P: maximum load, $\mathrm{N}$

$\mathrm{t}$ : specimen thickness, mm

D: specimen diameter, $\mathrm{mm}$ 
In order to quantify the loss of strength due to water and freeze-thaw, the averages of the indirect tensile strengths of the samples in each group are taken and proportioned as shown in Equation 2.

$$
\operatorname{ITSR}=\mathrm{S}_{2} / \mathrm{S}_{1}
$$

Where:

ITSR: indirect tensile strength ratio

$\mathrm{S}_{1}$ : average tensile strength ratio of the unconditioned subset, $\mathrm{kPa}$

$\mathrm{S}_{2}$ : average tensile strength ratio of the conditioned subset, $\mathrm{kPa}$

The ITSR value and the resistance of the mixture to water damage are directly proportional. Usually 0.80 is considered the limit value. Asphalt mixtures with ITSR value lower than 0.80 are considered to be unresistant to water damage while higher ones are considered to be resistant [22].

\section{TEST RESULTS AND EVALUATIONS}

Indirect tensile strength tests were performed on Marshall samples produced with base and modified bitumen according to AASHTO T283 method. Indirect tensile strength (ITS) values obtained from the tests and the calculated indirect tensile strength ratio (ITSR) values of mixtures are illustrated in Figure 2 to Figure 5.

Particular attention was paid to the subject of identity in the production of all asphalt mixture briquettes with and without glass additive. For this purpose, samples with a difference between their practical densities greater than 20\%o were not used and new samples were produced. The briquettes produced with the same mixtures type gave consistent indirect tensile strength values among themselves.

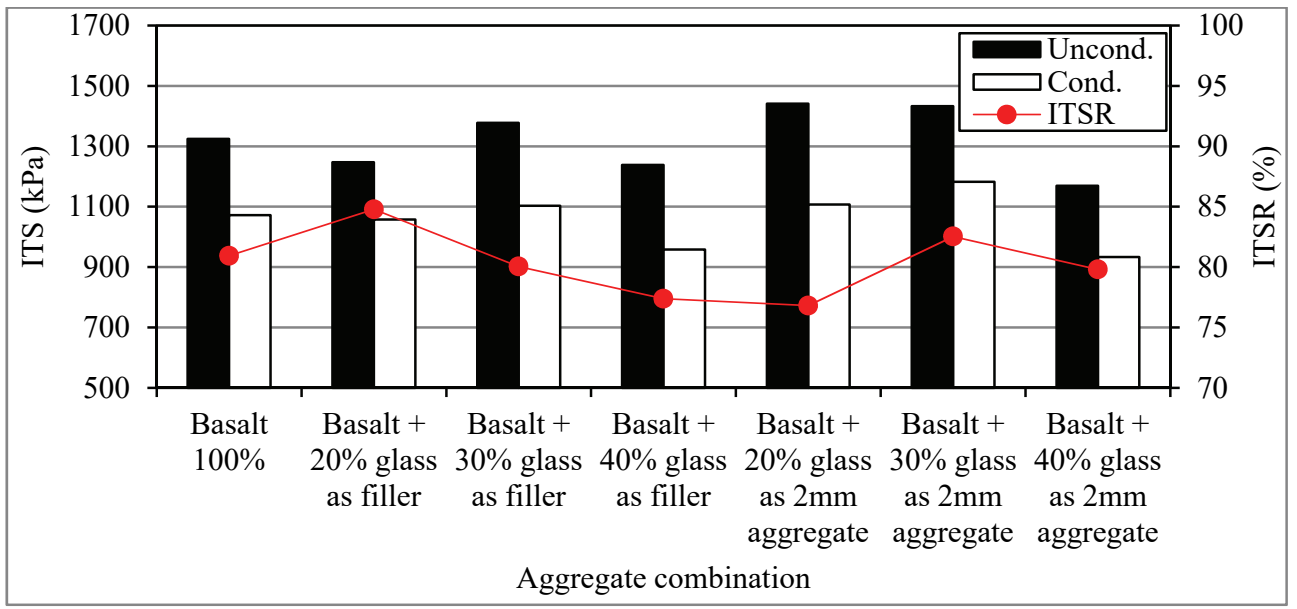

Figure 2 - Average ITS and ITSR values of control mixtures 


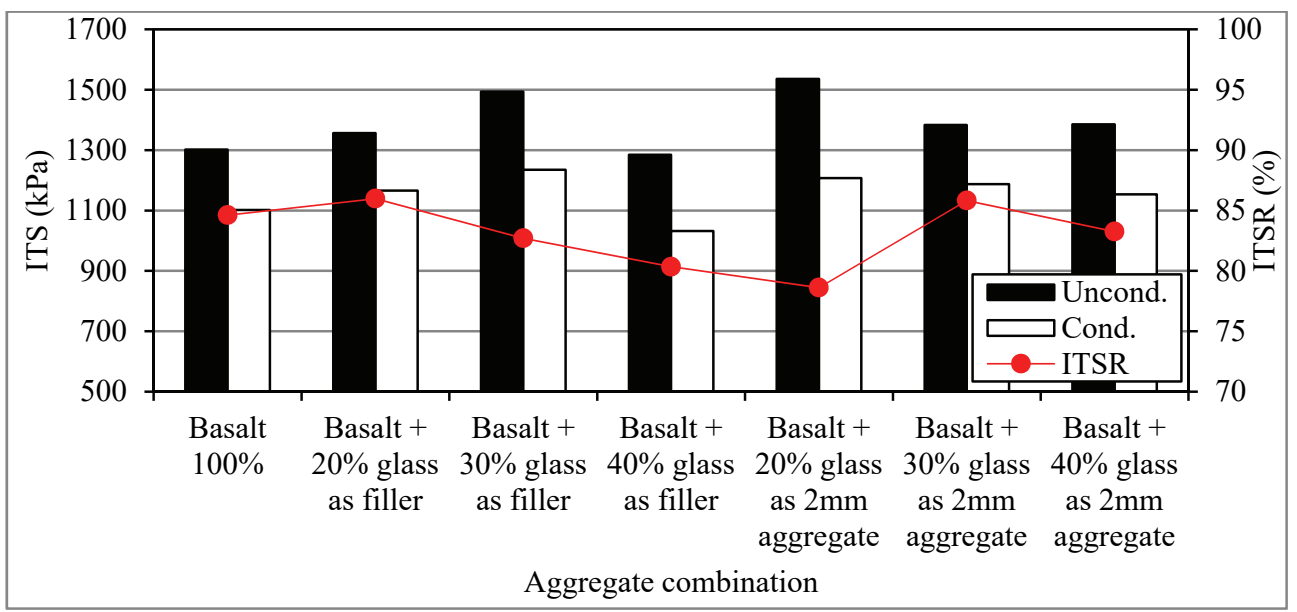

Figure 3 - Average ITS and ITSR values of SBS modified mixtures

Crushed glass particles were used as aggregate substituted for both filler and $2 \mathrm{~mm}$ fine aggregate in asphalt mixture. In addition, hydrated lime (HL) and SBS additives were chosen as additional performance enhancers. In the control mixtures (without HL and SBS), it is seen from Figure 2 that there is a decrease in tensile strength values in all mixtures with glass particles added $40 \%$. However, with the reduction of glass aggregate ratio (except for $20 \%$ glass filler) ITS values of unconditioned samples have increased. In SBS- and HL-modified mixtures (Figure 3 and Figure 4), only 40\% glass filler substitutes gave lower tensile strength values than those without any glass aggregates. In all other options, higher indirect tensile strengths were obtained. ITS values of the conditioned samples decreased significantly.

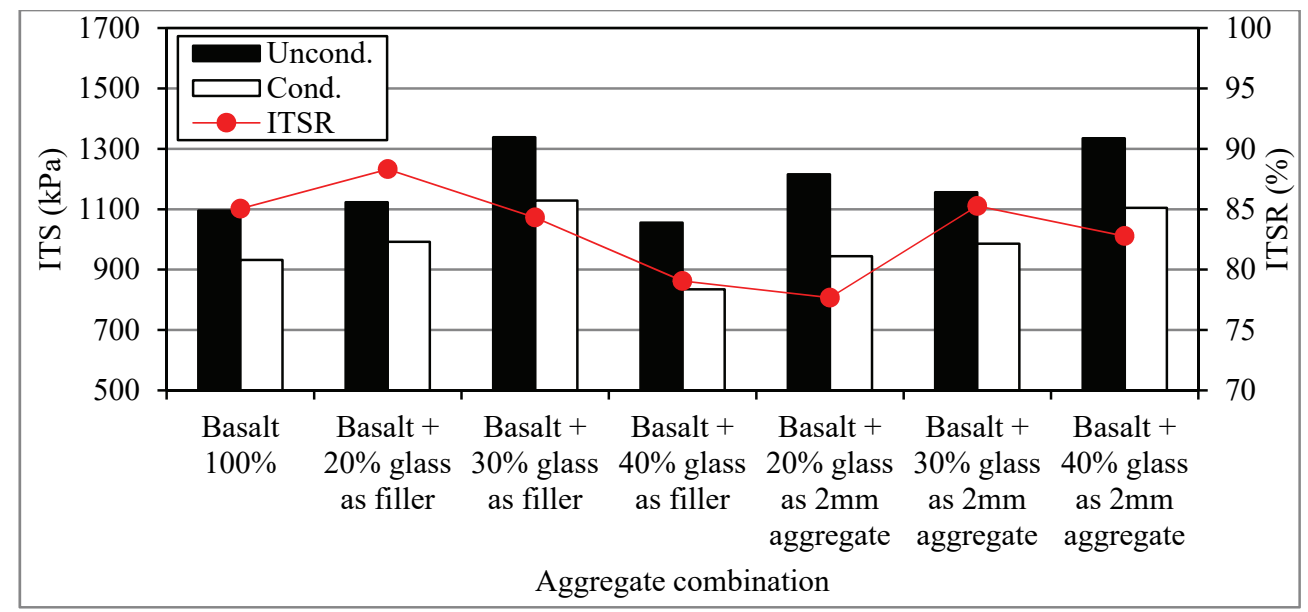

Figure 4 - Average ITS and ITSR values of HL modified mixtures 


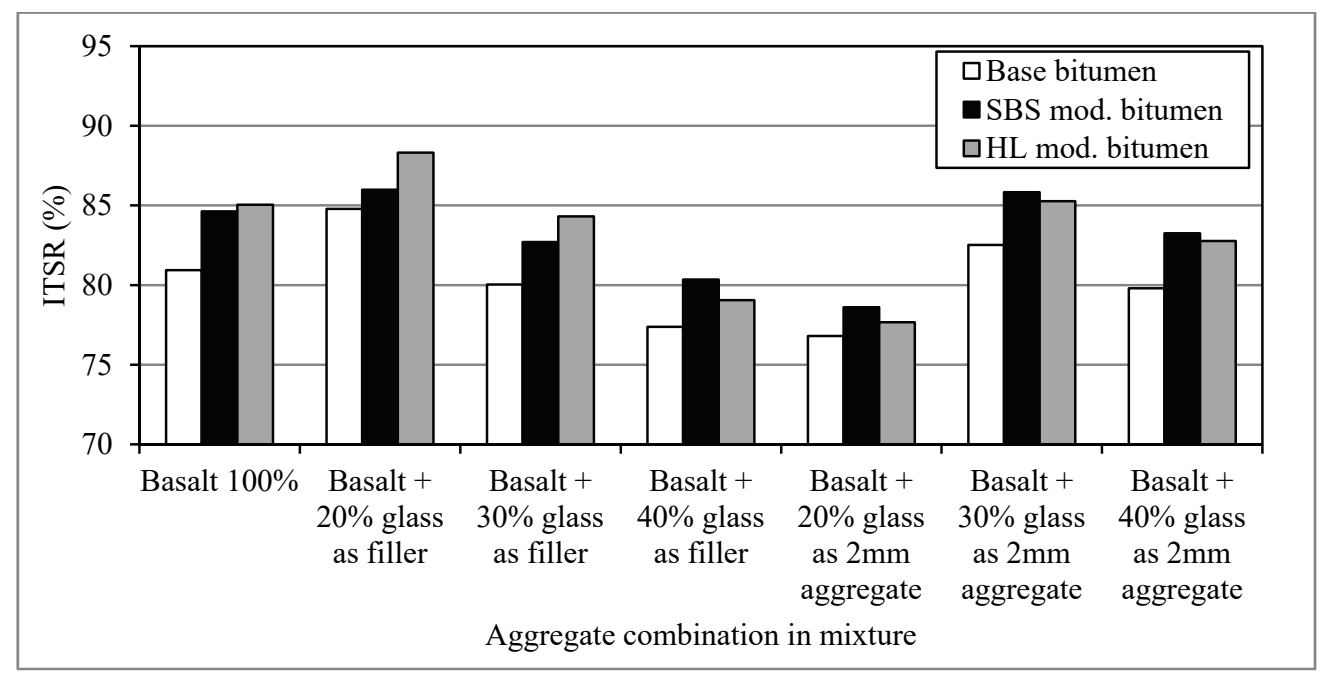

Figure 5 - Relationship between crushed glass size - ratio and water damage

As shown in Figure 5, indirect tensile strength ratios (ITSR) of both control mixtures and mixtures including glass aggregates were increased by SBS and HL modification. When $20 \%$ glass filler were used instead of basalt filler, higher water resistance was obtained compared with the control mixture. When the ratio of glass filler in the aggregate increases, the resistance to water damage decreases. When $2 \mathrm{~mm}$-sized glass aggregates are added, the best results are obtained with a participation rate of $30 \%$.

Ongoing studies have demonstrated that optimum mixture performance can best be obtained when $10 \%$ to $15 \%$ crushed glass is used as a fine aggregate substitute in asphalt mixes for road pavements. The major concern is the lack of absorption of bitumen by glass and the hydrophilic surface properties of glass that contribute to the water damage of glassphalt pavements. There is a potential to substitute depleting natural aggregates with crushed glass in asphalt mixes. This is based on the finding that asphalt mixtures with crushed glass could outperform conventional dense-graded mixtures in terms of permanent deformation, and they have a comparable fatigue resistance at low strains. The higher stiffness behavior exhibited by the glass mix at $20^{\circ} \mathrm{C}$ and $40^{\circ} \mathrm{C}$ determines that this mix can provide better resistance to permanent deformation than most conventional medium continuously-graded asphalt mixes. It is important to state that these conclusions pertain only to the crushed glass evaluated in this study and the specified design aggregate grading used, and cannot be transferred to any other crushed glass from different sources. Yet, these conclusions are based only on the properties of the mixes as determined in the laboratory [23].

The use of glass tends to reduce the VMA and air voids in Marshall Specimens; therefore, optimum asphalt binder content will also be decreased. Neither resilient modulus nor indirect tensile strengths are adversely affected by the addition of glass up to 15 percent. Although both wet strength and retained tensile strength ratios were unaffected by the percentage of glass, some separation at the asphalt glass interface was observed. A maximum of 15 percent crushed recycled glass should be allowed (100 percent passing a $9.5 \mathrm{~mm}$ sieve and a 
maximum of 6 percent passing a $75 \mu \mathrm{m}$ sieve) in hot mix asphalt mixes. There is little monetary incentive to use recycled glass at the present time because the cost of glass varies considerably [24].

In this study, the effect of glass granule size on water damage (stripping) is evaluated in asphalt pavements. The glass granules were used in two different sizes (filler and $2 \mathrm{~mm}$ sizes) and three different contents $(20 \%, 30 \%, 40 \%)$. The basalt aggregate was selected as coarse, fine and filler material. Both conventional control mixtures and SBS polymer and hydrated lime modified blends were tested with these alternatives. Indirect tensile strength test was applied to both dry briquettes and conditioned briquettes with the specified water damage conditioning system. In terms of water damage, the glass granule additive is in better interaction with the SBS polymer than the hydrated lime. For control mixtures, SBS polymer and hydrated lime likewise increase resistance to water damage. If glass granules are used as filler material, $20 \%$ ratio is a suitable choice because control and modified mixtures show higher resistance to water damage at this rate of use. In $20 \%$ glass filler granule, SBS and hydrated lime options, the resistance to water damage is synergistically increased compared with the control mixtures. The $2 \mathrm{~mm}$ glass granule size has negligible effects on all mixtures on water damage. In terms of water damage, if glass granules are used as fillers, both modified mixtures give higher water resistance. It is more reasonable to use filler size in blends of glass granules. The indirect tensile test shows the load-spreading capacity of the mixtures. When the conditional indirect tensile strength values are considered together with the interpretation of water damage, $20 \%$ of glass granule is considered suitable as filler. In this respect, it can be evaluated that waste glass can be used as a performance enhancer in asphalt mixtures. The mixture is judged to provide a higher homogeneity. When the filler material is lacking, this can be done with glass granules. Glass filler is also performs as antistripping agents. In addition, glass filler can be successfully used in blends of polymer and hydrated lime. Even if the aggregate is entirely selected as a basalt aggregate, the granular glass is tested to be successful in terms of water damage. Although basalt aggregates are generally prone to water damage (stripping), the glass granule has a performance enhancing effect. It is also contemplated that the use of lime at the point of manufacturing process of glass, this content has an anti-stripping additive effect at this point. In asphalt mixtures, the waste glass can be used at the point of recycling in terms of environmental sustainable approaches.

\section{CONCLUSIONS}

In this study asphalt mixtures using waste glass are examined in different gradations and SBS polymer and hydrated lime admixtures have also been tried. It is possible to reach the following results. In view of stripping, the glass granule additive is in better interaction with the SBS polymer than the hydrated lime. If glass granules are used as filler material, $20 \%$ ratio is a suitable choice. In $20 \%$ glass filler granule, SBS and hydrated lime options, the resistance to stripping is synergistically increased compared with conventional mixes. The 2 $\mathrm{mm}$ glass granule size has negligible effect on all mixtures against water damage. It is more reasonable to use filler size in blends of glass granules. Waste glass can be used as a performance enhancer in asphalt mixtures. According to these results, glass filler could be considered among anti-stripping agents in hot mix asphalt. 


\section{Symbols}
AH-70 : Heavy duty bitumen
CR : Crumb rubber
HL : Hydrated lime
ITS : Indirect tensile strength
ITSR : Indirect tensile strength ratio
RAP : Reclaimed asphalt pavement
RCA : Recycled construction aggregate
SBS : Styrene-butadiene-styrene
VMA : Voids in the mineral aggregate

[1] Tahmoorian F., Samali B., Tam W.Y., Yeaman J., Evaluation of Mechanical Properties of Recycled Material for Utilization in Asphalt Mixtures, Applied Sciences, 7, 763, 2017.

[2] Wu S., Yang W., Xue Y., Preparation and Properties of Glass-asphalt Concrete, Key Laboratory for Silicate Materials Science and Engineering of Ministry of Education, Wuhan University of Technology, Wuhan 430070, P.R China, 2004.

[3] Clean Washington Center, CWC. Best practices in glass recycling, 2005.

[4] Shafabakhsh, G.H., Sajed, Y., 2014. Investigation of dynamic behavior of hot mix asphalt containing waste materials, case study: glass-cullet. Case Studies in Construction Materials 1, 96-103, 2014.

[5] Arabani, M., 2011. Effect of glass-cullet on the improvement of the dynamic behaviour of asphalt concrete. Construction and Building Materials, 25 (3), 1181-1185, 2011.

[6] Afkhamy Meybodi, P., Khani Sanij, H., Hosseini, S.H., Olazar, M., Effect of Crushed Glass on Skid Resistance, Moisture Sensitivity and Resilient Modulus of Hot Mix Asphalt Arabian Journal for Science and Engineering, 44(5), 4575-4585, 2019.

[7] Su, N. and Chen, J.S., Engineering Properties of Asphalt Concrete Made with Recycled Glass, Resources Conservation and Recycling, 35(101), 259-274, 2002.

[8] Huang, Y., Bird, R.N., Heidrich, O., A review of the use of recycled solid waste materials in asphalt pavements, Resources, Conservation and Recycling 52, 58-73, 2007.

[9] Behbahani, H., Ziari, H., Kamboozia, N., Khaki, A.M. ve Mirabdolazimi, S.M., Evaluation of Performance and Moisture Sensitivity of Glasphalt Mixtures Modified with Nanotechnology Zycosoil as an Anti-Stripping Additive, Construction and Building Materials, 78, 60-68, 2015. 
[10] Issa, Y., Effect of Adding Crushed Glass to Asphalt Mix, Archives of Civil Engineering, 62, 2, 2016.

[11] Salem, Z.T.A., Khedawi, T.S., Baker, M. B., ve Abendeh, R., Effect of Waste Glass on Properties of Asphalt Concrete Mixtures, Jordan Journal of Civil Engineering, 11 (1), 117-131, 2017.

[12] Arabani, M., Mirabdolazimi, S. M. Evaluation of the effect of the use of waste glass cullet in increasing the lifetime of HMA. In: International congress on civil engineering, Iran, Shiraz University, 2009.

[13] Liao, Y., Wu, H., Yi, L. The enhancement effect of hydrated lime on glassphalt concrete. Applied Mechanics and Materials, 670-671, 423-427, 2014.

[14] Marti, M.M., Mielke, P.E.A., Synthesis of Asphalt Recycling in Minnesota, Minnesota Local Road Research Board, Synthesis Report 2002-32, 2002.

[15] Jasim, A.A., By Using Waste Glass as Secondary Aggregates in Asphalt Mixtures, International Journal of Advanced Research 2, 41-46, 2014.

[16] Meyer, C., Egosi, N., Andela, C., Concrete with Waste Glass as Aggregate, Recycling and Re-use of Glass Cullet", Dhir, Dyer and Limbachiya, editors, Proceedings of the International Symposium Concrete Technology Unit of ASCE and University of Dundee, March 19-20, 2001.

[17] A summary of the Sectorial Agenda, bi_ozet.com, (ŞIŞECAM) and (EBRD) will skip partnership with Turkey in glass recycling sector editorbiozet, June 28, 2016.

[18] Turkey Glass and Glass Products Industry Assembly Industry Report, Turkey Union of Chambers and Commodity Exchanges / www.tobb.org.tr, ISBN :978-605-137-29902012, 2012.

[19] Turkish Highways Technical Specification, General Directorate of Turkish Highways, Technical Research Department, Ankara, Turkey, 2013.

[20] İskender, C., Effect of Glass Aggregate Size and Aggregate Gradation on Asphalt Pavement Performance, Master Thesis, Karadeniz Technical University, Institute of Natural Sciences, Trabzon, Turkey, 2017.

[21] Standard method of test for resistance of compacted asphalt mixtures to moistureinduced damage, AASHTOT283, American Association of State Highway and Transportation Officials, Washington, D.C., USA, 2014.

[22] Liang, R.Y., Resistance of Compacted Bituminous Mixture to Moisture Induced Damage for Superpave, Department of Civil Engineering, University of Akron, Akron, 2008.

[23] Anochie-Boateng, J.K, George, T.B., Exploring Waste Glass in Hot-Mix Asphalt, Roads \& Bridges, IMIESA April, 31-34, 2017.

[24] Kandhal, P.S., Waste Materials in Hot Mix Asphalt - An Overview, National Center for Asphalt Technology, NCAT Report No. 92-6, December 1992. 
